\title{
Economic Realities and Consequences of the COVID-19 Pandemic-PART I: Financial Markets and Monetary Policy
}

Fernando Martin, Research Officer and Economist

T he measures to combat the COVID-19 pandemic will substantially reduce economic activity for an uncertain period. The size, scope, and speed of this economic contraction, as well as the great uncertainty surrounding policy and economic outcomes, are unprecedented. As a result, financial markets have been under great stress, prompting a quick reaction by the Federal Reserve.

\section{The Federal Reserve has taken} quick action to aid financial markets.

Stock prices dropped more than 30 percent between February 19 and March 23. In comparison, the stock market fell 57 percent peak to trough (October 2007 to March 2009) during the Financial Crisis of 2007-09 (Figure 1).
Expected near-term stock volatility, as measured by the VIX index, has also increased to historic highs. We have witnessed days of sharp declines but also of big recoveries, and the stock market has been very sensitive to policy news (Figure 2).

The stock market has partially recovered since March 23, recovering about 14 percent by March 27, based on news about Fed intervention and a deal on a fiscal stimulus package.

The aftermath of the previous financial crisis witnessed increased financial regulation and oversight. Regulators now subject banks, bank-holding companies, and systemically important financial institutions to closer monitoring and supervision. The financial sector has moved toward more liquid and safe assets; in particular, asset holdings have shifted from loans to Treasuries, government-backed securities, and corporate equities. However, this consolidated view masks the risks present in some parts of the system.

Figure 1

S\&P 500

Financial Crisis 2007-09

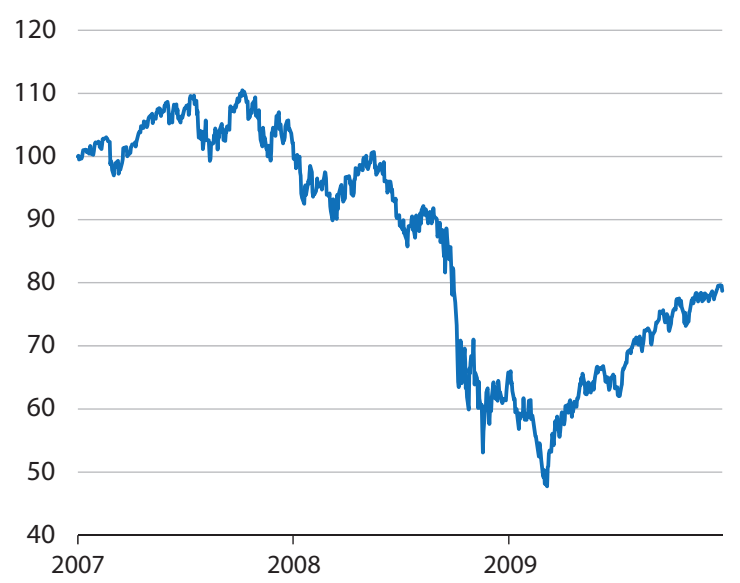

COVID-19 Pandemic

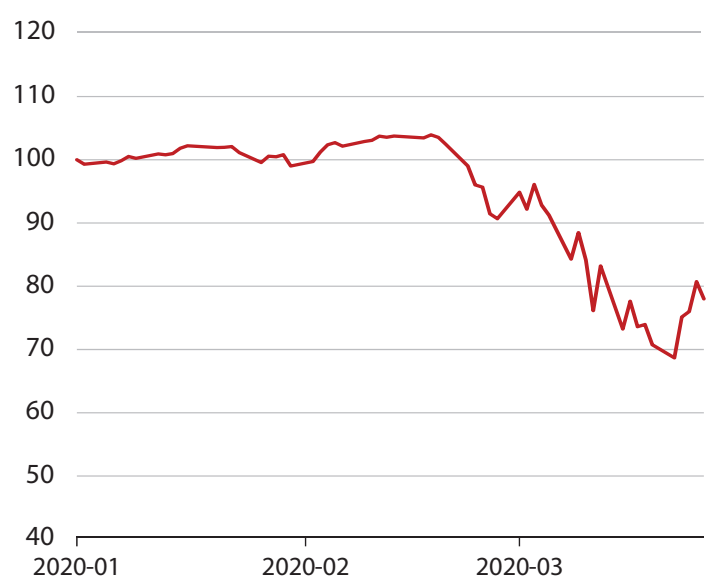

NOTE: The index is normalized to 100 at the beginning of each sample, 1/3/2007 for left panel and 1/2/2020 for right panel. SOURCE: Yahoo! Finance and author's calculations. 
Figure 2

\section{CBOE Volatility Index: VIX}

Financial Crisis 2007-09

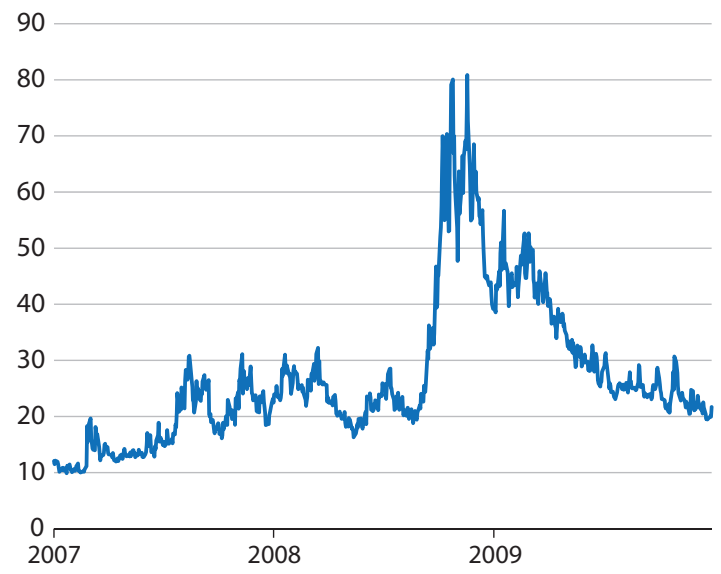

SOURCE: FRED ${ }^{\circledR}$, Federal Reserve Bank of St. Louis.

Figure 3

30-Day Nonfinancial Commercial Paper Interest Rate

Financial Crisis 2007-09

Percent

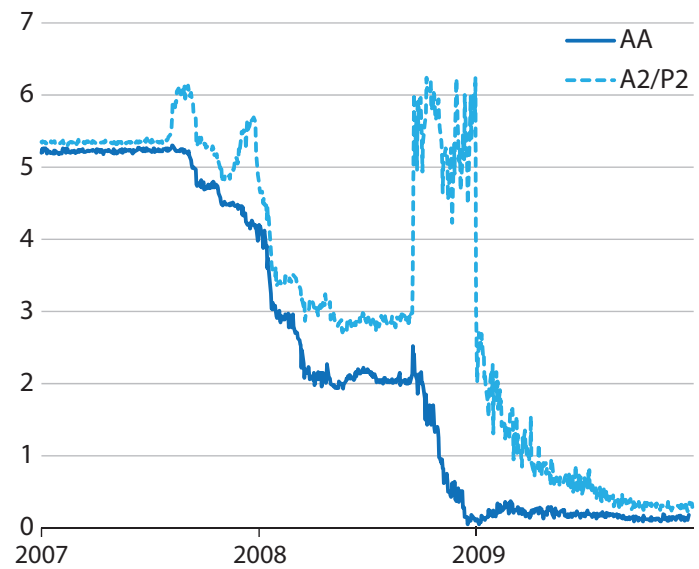

COVID-19 Pandemic

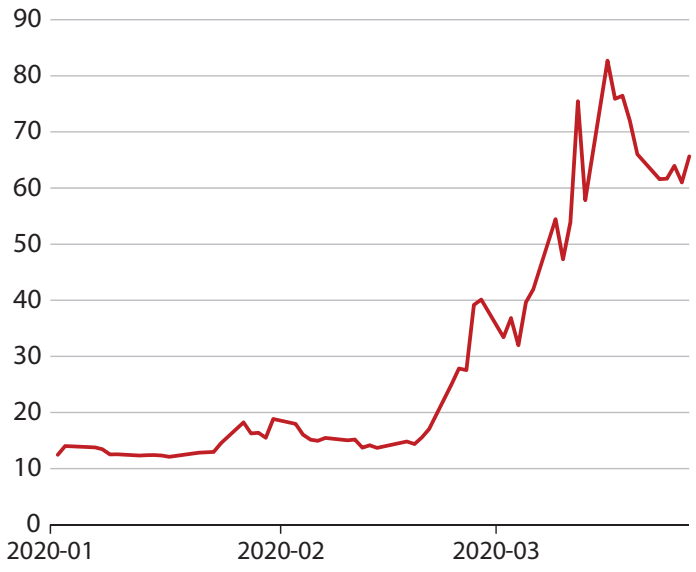

Percent
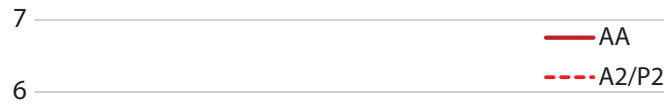

5

4

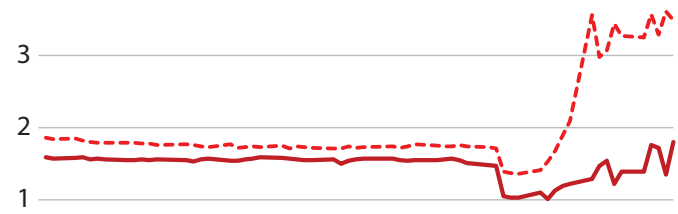

$2020-01 \quad 2020-02 \quad 2020-03$

NOTE: For an explanation of commercial paper ratings, see https://www.federalreserve.gov/releases/cp/about.htm. SOURCE: FRED ${ }^{\oplus}$, Federal Reserve Bank of St. Louis.

At the retail level, there have been (as of yet, anyway) no bank runs and the payment and credit systems appear to be operating normally. Households can continue to make transactions virtually, without disruptions or fear.

The institutional sector is a different story. Preliminary reports indicate that institutional investors (e.g., hedge and pension funds) are building up cash reserves; money market funds and commercial paper markets have been stressed; and highly leveraged financial firms, such as real estate investment funds, are getting margin calls that force them to sell liquid assets. Even government bond markets have experienced significant ups and downs (Figure 3).

Both investment grade and speculative corporate debt yields have sharply increased, and corporations have drawn on credit lines (Figure 4). The spike in highly rated corporate debt spreads is worrisome, as it may signal excessive risk aversion (or even panic-like behavior) from investors. It could, however, simply reflect the fact that even normally 


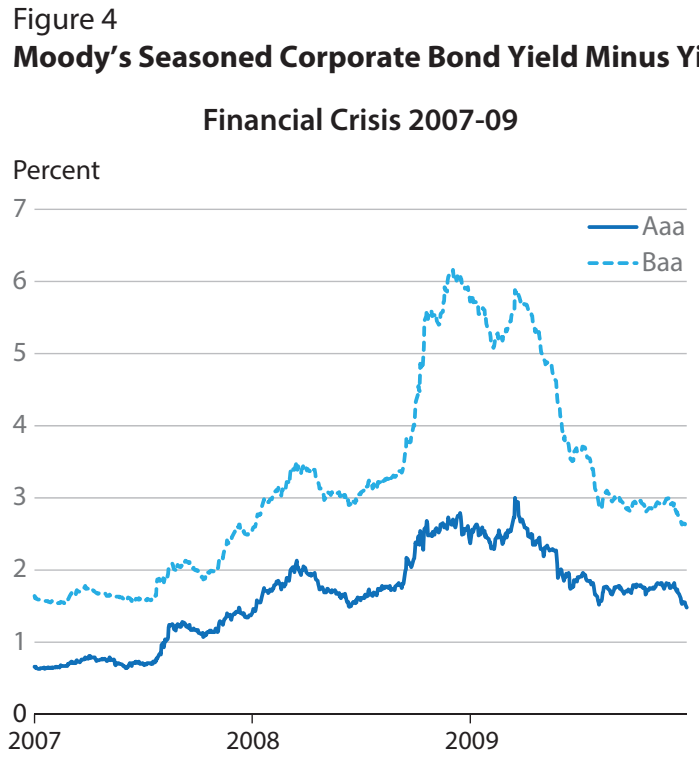

SOURCE: FRED ${ }^{\circledR}$, Federal Reserve Bank of St. Louis.

Figure 5

TED Spread

Financial Crisis 2007-09

Percent

5

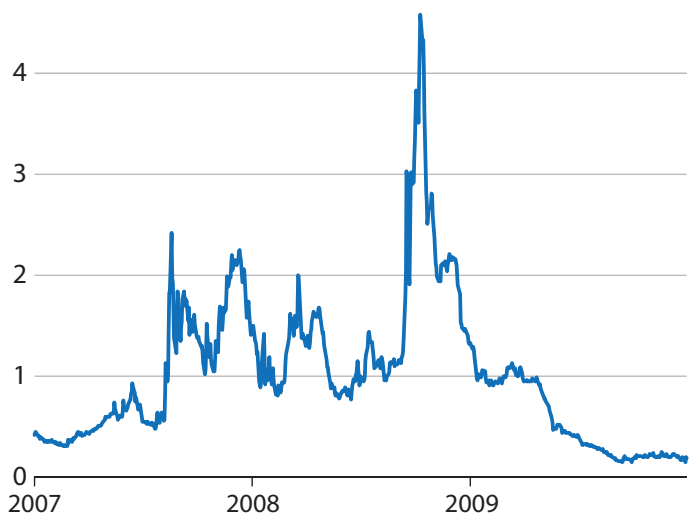

SOURCE: FRED ${ }^{\oplus}$, Federal Reserve Bank of St. Louis.

safe corporations may suffer severely during the shutdown measures.

During the Financial Crisis of 2007-09, uncertainty drove a large portion of the panic. Investors were uncertain about the value of structured products related to subprime mortgages (e.g., mortgage-backed securities and asset-backed collateralized debt obligations) and the exposure of financial institutions to subprime risk. This type of uncertainty is likely not as severe in the present context.
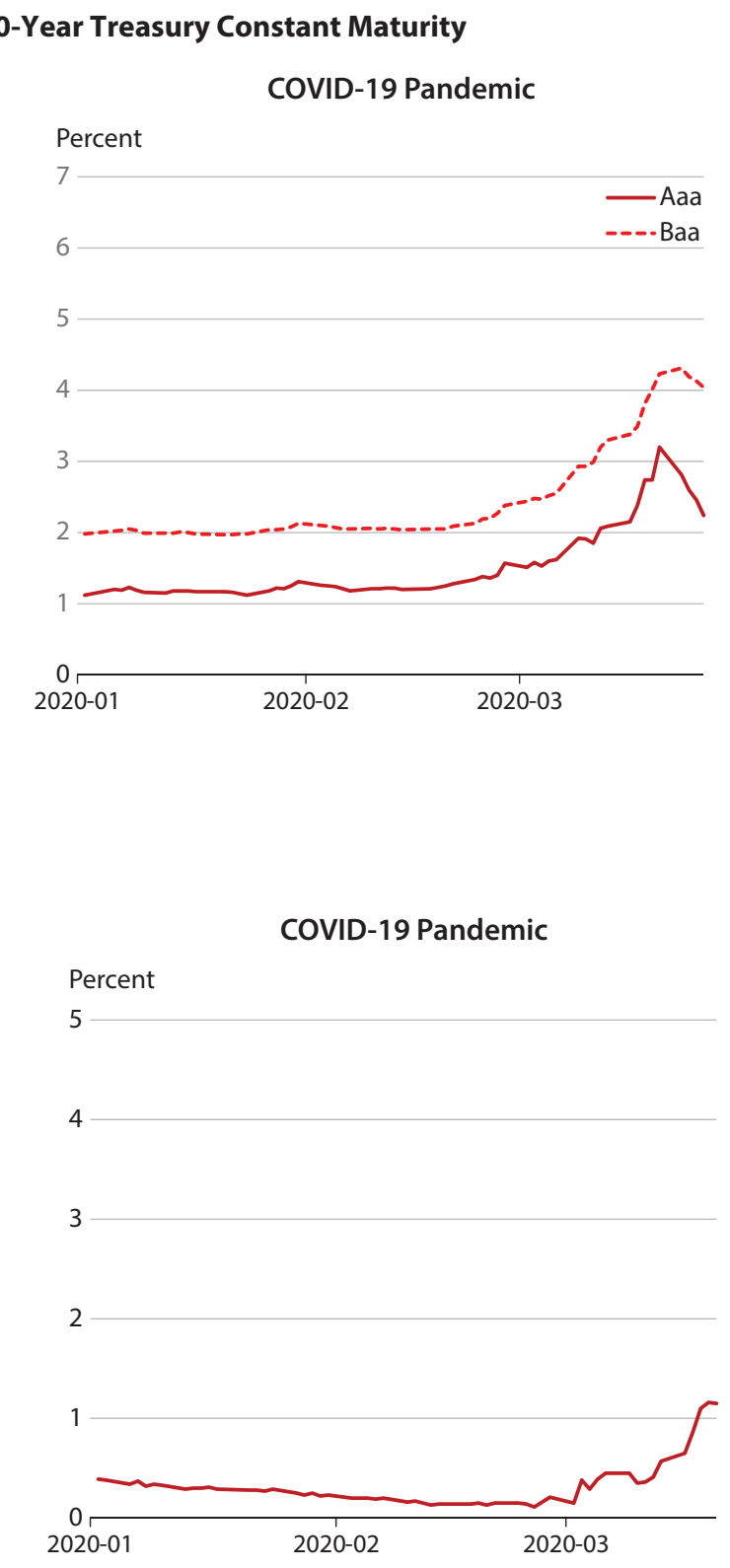

Credit risk - the risk of default on a debt-was another big element in the financial crisis, and it remains to be seen what role it will play in the current situation. Credit risk, as measured by the TED spread, has increased in March, though early Fed policy may have helped prevent it from rising as much as during the Financial Crisis of 2007-09 (Figure 5).

During crises in financial markets-no matter what the cause- the Fed tries to alleviate the stress and ensure the 
Figure 6
Effective Federal Funds Rate

Financial Crisis 2007-09

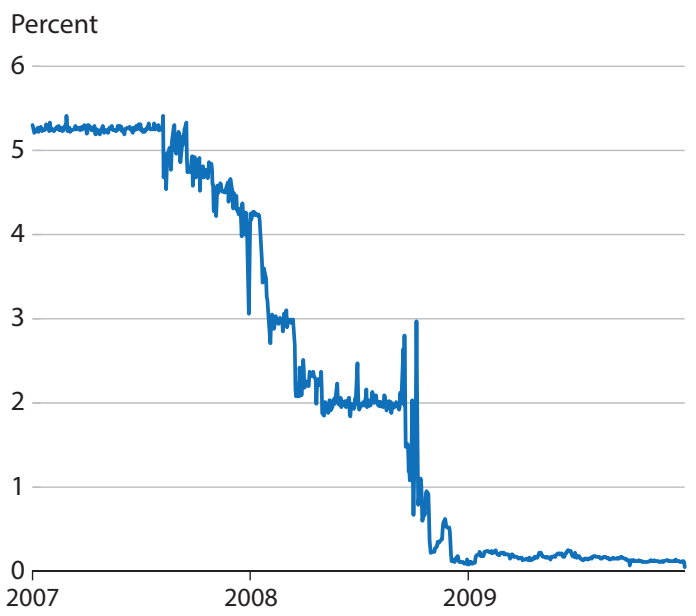

SOURCE: FRED ${ }^{\circledR}$, Federal Reserve Bank of St. Louis.

adequate provision of liquidity. To this effect, the Fed lowered its policy rate back to zero and opened a series of credit facilities, echoing its response during the financial crisis (Figure 6). Examples of these facilities include the Money Market Mutual Fund Liquidity Facility, the Primary Dealer Credit Facility, and the Commercial Paper Funding Facility. On March 23, the Fed adopted a whatever-it-takes policy stance, greatly expanding the classes of assets it is willing to purchase.

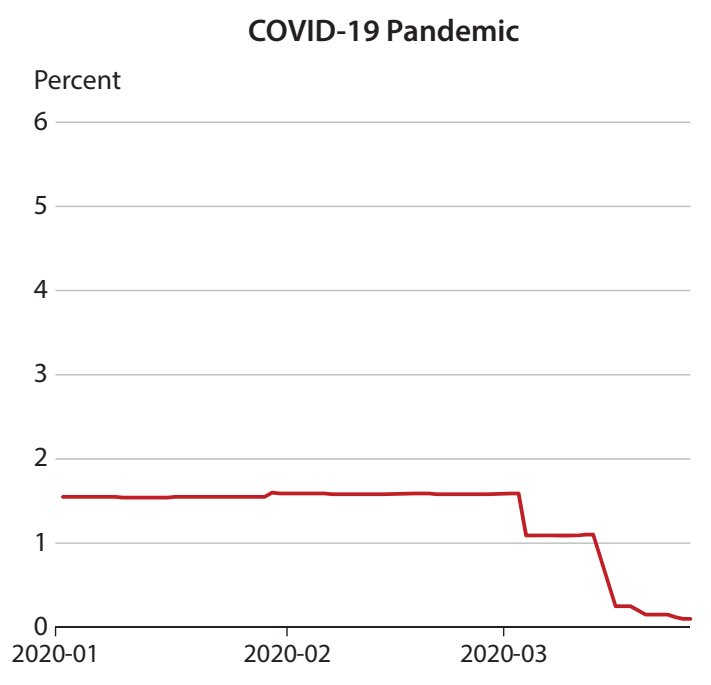

Despite the significant regulatory overhaul following the past financial crisis, the financial sector continues to exhibit areas of fragility, as evidenced above. The stress endured by institutional financial markets in the current situation has prompted the Fed to again step in to ensure their proper functioning and prevent a possible financial panic. In Part II of this essay I discuss the economy and fiscal policy response during the pandemic. 